\title{
A prospective randomized controlled trial comparing circumferential casting and splinting in displaced Colles fractures
}

\author{
Eric Grafstein, MD; ${ }^{* \dagger}$ Rob Stenstrom, MD, PhD; ${ }^{* \dagger}$ Jim Christenson, MD; ${ }^{* \dagger}$ Grant Innes, MD; ${ }^{\neq \S}$ \\ Robert MacCormack, MD; ${ }^{+\pi}$ Colin Jackson, MD; ${ }^{+\uparrow}$ Keith Stothers, MD; ${ }^{+\boldsymbol{\tau}}$ Tom Goetz, MD, MSc ${ }^{+\uparrow}$
}

\section{ABSTRACT}

Objective: Our primary objective was to determine the effectiveness of 3 immobilization methods (circumferential casting [CC], volar-dorsal splinting [VDS] and modified sugar-tong [MST] splinting) in maintaining the position of displaced distal radius fractures after successful closed reduction. Our secondary objective was to assess long-term functional outcomes associated with immobilization with fibreglass splinting versus standard $\mathrm{CC}$ in patients maintaining initial nonoperative reductions.

Methods: We conducted a prospective randomized singleblind controlled trial in patients over 18 years of age who presented to the emergency department with a displaced fracture of the distal radius requiring closed reduction. The primary outcome was loss of reduction (defined as radiologic slippage or the need for surgical fixation during the 3-4 week primary immobilization period after initial successful reduction). Secondary outcomes included DASH (disabilities of the arm, shoulder and hand) score, return to work, activities of daily living, wrist pain, range of motion and grip strength assessed at 8 weeks and 6 months.

Results: Thirty participants were randomly assigned to receive MST splinting, 31 to receive VDS and 40 to receive CC. Baseline characteristics were similar among groups. Radiographic loss of reduction occurred in 16\% (95\% confidence interval [Cl] $3.1 \%-28.9 \%)$ of participants in the VDS group, $20 \%(95 \% \mathrm{Cl} 7.6 \%-32.4 \%)$ in the CC group and $30 \%(95 \% \mathrm{Cl}$ $13.6 \%-46.4 \%)$ in the MST splinting group ( $p=0.17$ ). Based on multivariate analysis of variance, functional outcomes at 8 weeks were similar among groups $(p=0.89)$. DASH scores at 8 weeks and 6 months were similar among groups, based on 1-way analysis of variance ( $p>0.25)$.

Conclusion: Rates of loss in anatomic position were not statistically significant among the 3 types of dressings used. However, there was a clinically important trend of increased loss of reduction with the use of MST splinting. Functional outcomes at 8 weeks and 6 months were not significantly different between CC, VDS and MDS splinting. Ease of application and familiarity with use should guide clinical decisions when choosing a dressing type for displaced Colles fractures.

Keywords: distal radius (Colles) fracture, immobilization techniques, cast, splint, closed reduction, randomized controlled trial

\section{RÉSUMÉ}

Objectif : Notre principal objectif consistait à déterminer l'efficacité de 3 méthodes d'immobilisation (attelle plâtrée [AP], attelle palmaire ou dorsale [APD] et une attelle de type pince à sucre modifiée [APSM]) pour maintenir la position du radius distal avec déplacement après une réduction à foyer fermé réussie. Notre deuxième objectif était d'évaluer les résultats fonctionnels à long terme associés au maintien des réductions initiales non opératoires pour les immobilisations avec APD et AP.

Méthodes : Nous avons réalisé une étude prospective randomisée contrôlée à simple insu chez des patients de plus de 18 ans qui se sont présentés au service d'urgence pour une fracture du radius distal avec déplacement nécessitant une réduction à foyer fermé. La principale mesure de résultats était la perte de réduction (qui se définit comme le déplacement secondaire observé au contrôle radiologique ou la nécessité d'une réduction chirurgicale au cours des 3 à 4 semaines de l'immobilisation primaire après la réduction initiale réussie). Les mesures secondaires de résultats incluaient le score de DASH (incapacité fonctionnelle du bras, de l'épaule et de la main), les activités de la vie quotidienne, le retour au travail, les douleurs au poignet, l'amplitude des mouvements et la force de préhension évaluée à 8 semaines et à 6 mois.

Résultats : Nous avons assigné aléatoirement à 30 participants les attelles APSM, à 31 les APD et à 40 les AP. Les caractéristiques de base étaient semblables pour tous les groupes. Un déplacement secondaire à été détecté au contrôle radiographique chez $16 \%$ des participants du groupe

From the *Department of Emergency Medicine St. Paul's Hospital, Vancouver, BC, the †Faculty of Medicine, University of British Columbia, Vancouver, BC, the ¥Department of Emergency Medicine, University of Calgary, Calgary, Alta., the §Department of Emergency Medicine, Foothills Hospital, Calgary, Alta., and the IDepartment of Orthopedic Surgery, St. Paul's Hospital, Vancouver, BC

Submitted Mar. 15, 2008; Revised Feb. 28, 2009, Dec. 17, 2009; Accepted Mar. 1, 2010

This article has been peer reviewed.

CJEM 2010;12(3):192-200 
APD (intervalle de confiance [IC] à $95 \%$, de 3,1 à 28,9\%), chez $20 \%$ des participants du groupe AP (IC à $95 \%$, de 7,6 à $32,4 \%$ ) et chez $30 \%$ des participants du groupe APSM (IC à $95 \%$, de 13,6 à $46,4 \%)(p=0,17)$. Selon une analyse multivariée de la variance, les résultats fonctionnels à 8 semaines étaient similaires pour les trois groupes $(p=0,89)$. Les scores de DASH à 8 semaines et à 6 mois étaient similaires pour les trois groupes, selon une analyse unidirectionnelle de la variance $(p>0,25)$.

Conclusion : Les taux de non-maintien de la position ana- tomique n'étaient pas statistiquement significatifs pour les trois types d'attelle utilisés. Cependant, nous avons observé une tendance cliniquement importante d'augmentation de la perte de réduction avec I'utilisation de I'APSM. Les résultats fonctionnels à 8 semaines et à 6 mois n'étaient pas significativement différents pour les trois types d'immobilisation utilisés. La facilité d'application et la familiarité avec une méthode d'immobilisation devraient guider les décisions cliniques au moment de choisir un type d'attelle pour les fractures de Pouteau-Colles avec déplacement.

\section{INTRODUCTION}

Fracture of the distal radius (Colles fracture) is commonly seen in the emergency department (ED) and many displaced distal radius fractures require reduction and some form of immobilization. ${ }^{1}$ Nonoperative immobilization techniques include circumferential casting (CC) (Fig. 1), modified sugar-tong (MST) splinting (also known as muenster splinting) (Fig. 2) and volar-dorsal splinting (VDS) (Fig. 3). Rigid circumferential casts have limited capacity to accommodate ongoing limb swelling and may cause pressure sores, increased tissue pressure and neurovascular compromise. ${ }^{2,3}$ For these reasons, many physicians apply circumferential casts and then split one or both sides. This practice is time-consuming and may theoretically compromise the stability of the immobilization.

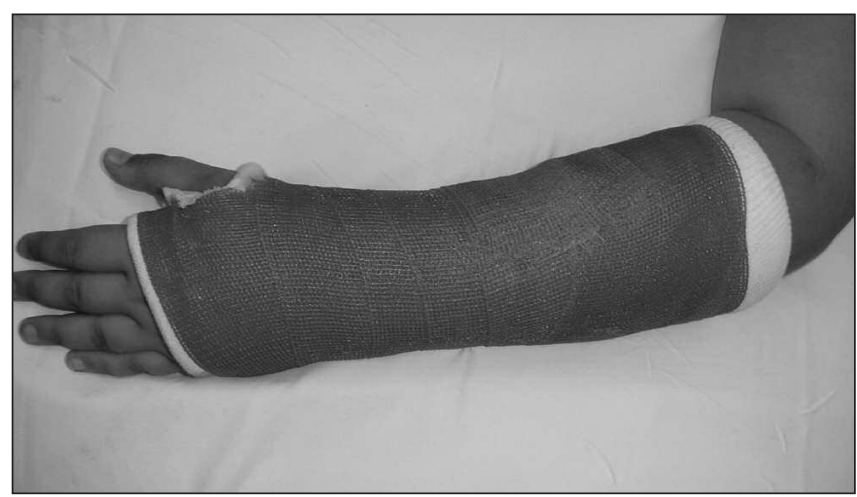

Fig. 1. Circumferential cast.

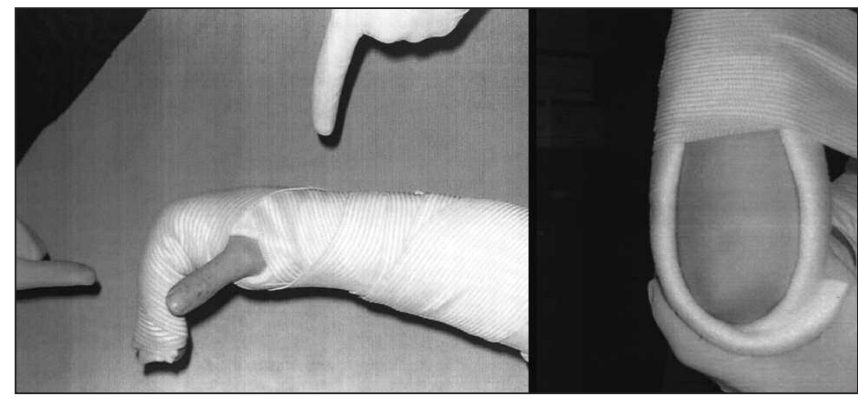

Fig. 2. Modified sugar-tong (muenster) splint.
Noncircumferential splints accommodate tissue swelling with more comfort and less risk of pressurerelated complications. ${ }^{4}$ Moreover, prepackaged fibreglass splinting materials are easier to apply than circumferential casts and durable enough to last the duration of the immobilization period. ${ }^{5}$ Because this material is harder to mould, it is possible that VDS is less effective in maintaining fracture anatomy after successful reduction.

An MST immobilization technique (Fig. 2) has been advocated in some North American hand and wrist orthopedic centres based on the concept that better functional outcomes can be obtained with more comprehensive immobilization. ${ }^{6}$ The MST splint is essentially a volar splint combined with a dorsal splint that extends proximally around the elbow, blocking pronation and supination. The dorsal component of the splint extends distally, immobilizing the metacarpophalangeal joints at $75^{\circ}-90^{\circ}$ of flexion and the interphalangeal joints in a position of function.

To date, no studies have compared the effectiveness of synthetic splinting with that of CC in the management

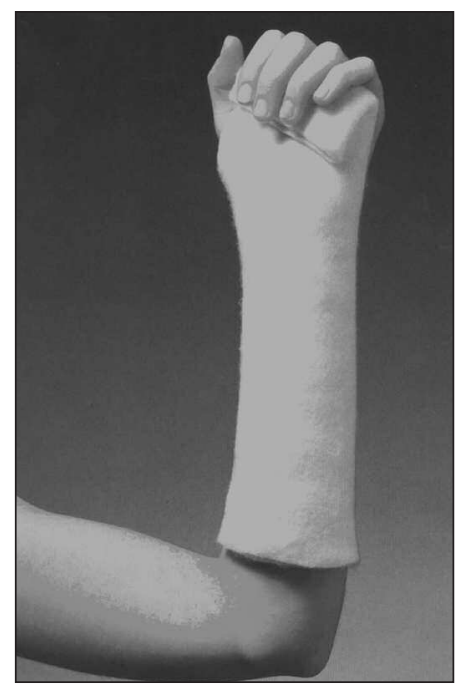

Fig. 3. Volar-dorsal splint. 
of displaced Colles fractures. Our primary objective was to determine the effectiveness of the 3 immobilization methods in maintaining the position of displaced distal fractures after successful closed reduction. Our secondary objective was to assess 6-month functional outcomes associated with fibreglass splint immobilization versus standard CC in patients maintaining initial nonoperative reductions.

\section{PATIENTS AND METHODS}

\section{Study design}

This randomized controlled trial compared the effectiveness of fibreglass VDS, plaster CC and fibreglass MST splinting in maintaining reduction of distal radius fractures. The research ethics board at Providence Health Care granted approval for the study protocol, and all patients provided written informed consent before study entry.

\section{Setting and patients}

This study was carried out at St. Paul's Hospital (SPH), a Vancouver tertiary care hospital, the Royal Columbian Hospital (RCH), a community referral centre in New Westminster, BC, and Mount St. Joseph's Hospital (MSJ) and St. Vincent's Hospital (SVH), both small urban community hospitals in Vancouver, BC. The treating emergency physicians at 3 sites (SPH, MSJ, $\mathrm{SVH})$ are experienced in the initial reduction of Colles fractures. The pattern of practice at $\mathrm{RCH}$ is for all displaced fractures to be referred to the orthopedic resident or consultant for reduction and further treatment.

Patients over 18 years of age who presented to the ED with a displaced upper extremity fracture involving the distal radius were eligible for inclusion. Patients were excluded if they had any of the following: an open fracture; a previous displaced fracture involving the same or contralateral distal radius; neuromuscular deficits or cerebrovascular accident of either upper extremity that impaired functional outcome assessment; concurrent carpal bone fractures or dislocations; unstable fractures requiring primary open reduction internal fixation or external fixation (based on the opinion of the attending orthopedic surgeon); skin allergy or sensitivity to either of the immobilization materials; Smith, Barton or chauffeur fractures; neurovascular compromise of the affected limb; bilateral distal radius fractures that prevented follow-up comparison with a normal contralateral limb; other significant and concurrent injuries in the ipsilateral extremity. Patients were also excluded if the distal radius fracture was not displaced or if the reduction performed in the ED did not meet the criteria for successful fracture reduction (Box 1).

\section{Study procedures}

Before study initiation, participating physicians underwent a series of teaching sessions to maximize uniform splinting and casting technique. Eligible participants who presented with a distal radius fracture requiring closed reduction provided informed consent and were randomly assigned to the Dynacast Prelude fibreglass (Smith \& Nephew) VDS group, plaster CC group or the Dynacast Prelude fibreglass MST group, by opening a sealed envelope with a specific group allocation, previously determined using a table of random numbers.

Patients underwent immediate closed reduction. Procedural sedation using the emergency physician's preferred medications (typically fentanyl/midazolam or ketamine or propofol, or some combination of these drugs) was employed. Patients with unsuccessful reductions were excluded from the study and referred for possible open reduction internal fixation; those with

\section{Box 1. Outcome definitions}

1. Undisplaced fracture

An undisplaced fracture is a fracture with $\leq 2 \mathrm{~mm}$ of distal radius shortening, $\leq 0^{\circ}$ of dorsal angulation of the distal radial articular surface and $\leq 1 \mathrm{~mm}$ of intra-articular step deformity. Patients with undisplaced fractures were excluded from the study.

2. Fracture requiring reduction

Fractures requiring reduction include those with $\geq 5 \mathrm{~mm}$ of distal radius shortening, $\geq 10^{\circ}$ dorsal angulation of the distal radial articular surface, $10^{\circ}$ of radial inclination or a $\geq 2 \mathrm{~mm}$ intra-articular step deformity. In patients $<50$ years of age, only $2 \mathrm{~mm}$ of radial shortening, $0^{\circ}$ of dorsal angulation of the distal radial articular surface and $1 \mathrm{~mm}$ of intra-articular step deformity were considered acceptable.

3. Successful reduction

Reduction is considered successful if the postreduction radiograph shows no significant shortening, angulation or step deformity, as defined above in 1.

4. Unsuccessful reduction

Reduction is considered unsuccessful if the postreduction radiograph shows shortening, dorsal angulation or intraarticular step deformity greater than described in 1 .

5. Failure of immobilization

Occurs if any follow-up radiograph shows loss of successful reduction after adequate position was documented on postreduction radiographs. 
successful reductions were immobilized as per their study assignment. Patients in the VDS group received short-arm VDS, extending from the palmar crease to a point 1 inch distal to the elbow flexion crease, wrapped with an elastic bandage and moulded with the wrist in a position of slight flexion, ulnar deviation and pronation (Fig. 3). Patients in the CC group had a short-arm plaster of Paris cast applied as described by Rockwood and Green (Fig. 1). ${ }^{2}$ Patients in the MST group received fibreglass VDS, in which the volar component extended to the palmar crease and the dorsal component extended proximally around the elbow, blocking pronation and supination, with the hand in a position of function (Fig. 2). In the MST group, after 3 weeks (when further slippage is unlikely and the risk of hand and elbow stiffness increases), VDS replaced the full aboveelbow dressing.

In all groups, a repeat reduction was attempted for primary failure of the reduction at the discretion of the emergency physician or orthopedic consultant. The repeat reduction used the initial assigned dressing group. The first postreduction radiograph showing adequate fracture position within a splint or cast served as the baseline comparison for follow-up films. Patients were provided with "event logs" to document any cast problems and unscheduled visits that occurred between follow-up visits.

\section{Follow-up}

Figure 4 describes the follow-up of patients. On day 2 or 3 , patients were telephoned and asked to describe their level of pain and to report any problems. At about 1 week, patients were examined by an orthopedic surgeon and radiography was performed to assess fracture position. At 3-4 weeks, the final study radiographs were taken to assess anatomic position of the distal radius. A senior orthopedic resident blinded to treatment group reviewed the radiographs and assessed them for angulation, shortening and joint congruity based on the criteria described in Box 1. To minimize bias, radiographs were read in a random nonsuccessive order. At 8 weeks and 6 months postfracture, patients returned for a functional outcome assessment, which included strength, pain, range of motion (ROM) (compared with the contralateral limb), activities of daily living (ADLs), ability to return to work (RTW) and DASH (disabilities of the arm, shoulder and hand) scores. ${ }^{3}$

At each visit, study nurses collected relevant followup data, including categorical pain scores (1-5), unscheduled cast-related physician visits, secondary reduction or surgical fixation, and skin breakdown or infection. Orthopedic surgeons were instructed not to change dressing types after randomization; consequently, patients remained in the group they were assigned to for 3-4 weeks, as long as the reduction held. If, during this time, the reduction slipped, the treatment was considered a failure, and the patient's treatment was managed at the surgeon's discretion.

\section{Outcomes}

Our primary outcome was the occurrence of loss of reduction, defined as radiologic slippage (Box 1) or the need for surgical fixation during the 3-4 week primary immobilization period after initial successful reduction. In patients who suffered one of these outcome events, treatment was considered to have failed for the primary outcome, and the patient was removed from follow-up and further analysis. Secondary outcomes included the following: grip strength, DASH score, ROM, ADLs and time to RTW.

\section{Data analysis}

Data were entered into an Access database (Microsoft Corp.) and then exported to Statistica (StatSoft). The statistical significance of observed differences in categorical outcomes, including the dichotomous primary outcome, was determined using $\chi^{2}$ analysis or Fisher exact test where appropriate. Because there were several functional outcomes that were highly correlated with each other, we used multivariate analysis of variance (MANOVA) to assess the statistical significance of differences between the normal and affected sides. Range of motion, ADLs and wrist pain - both at rest and with movement - were analyzed nonparametrically using $\chi^{2}$ and Kruskal-Wallis 2-way analysis of variance (ANOVA). We analyzed DASH scores using 2 separate 1-way ANOVAs. We adopted this approach instead of a 2-way repeated-measures ANOVA because of the smaller number of evaluable patients at the 6-month time point. The usual assumptions underlying ANOVA (homogeneity of group variances and normality of distribution) were satisfied for these data.

\section{Sample size}

Based on previous work by Schmalholz $z^{6}$ we expected a slippage rate of $22 \%$ in patients with Colles fractures. 
We felt it was very unlikely that $\mathrm{CC}$ would prove less effective than splints in preventing slippage; therefore, the sample size calculation was based on a 1-sided test. Setting alpha at 0.05 , beta at 0.20 , and delta, the clinically important effect size, at 0.2 for a dichotomous primary outcome variable, we required a sample size of 66 fractures per group. We arbitrarily chose the clinical effect size of 0.2 .

\section{RESULTS}

Between April 1999 and February 2003, 146 patients were screened and 122 were eligible for inclusion after a successful primary reduction (Fig. 5). Eleven patients were noncompliant and lost to follow-up, 2 had fracture patterns that led to exclusion and 8 had incomplete radiographic evaluation, leaving 101 in the study sample.

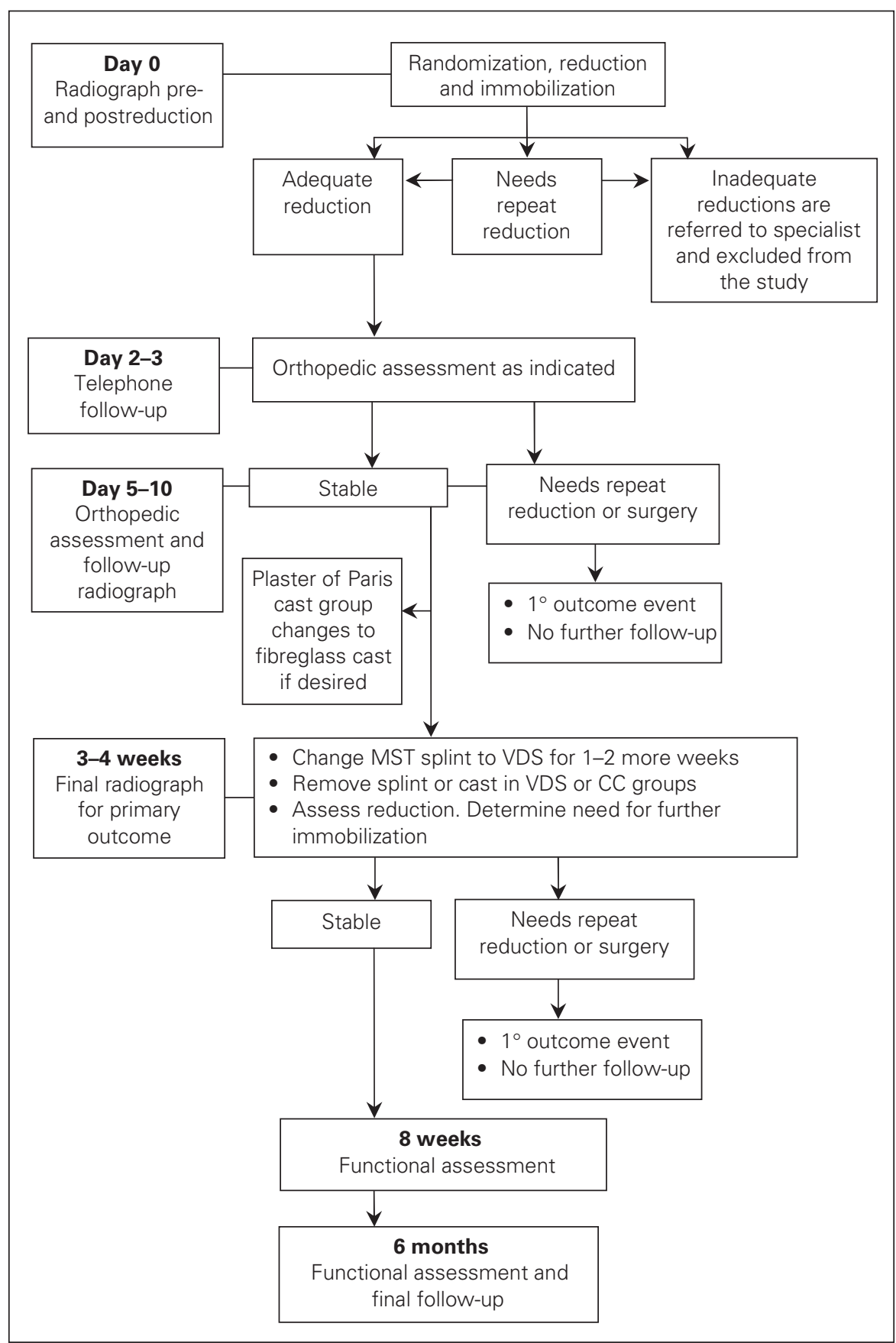

Fig. 4. Study flow chart describing the follow-up of patients. $\mathrm{CC}=$ circumferential cast; $\mathrm{MST}=$ modified sugar-tong; VDS = volar-dorsal splint. 
The study group included 30 patients in the MST group, 31 in the VDS group and 40 in the CC group. Eighty-two patients $(82 \%)$ were available for 8 -week functional outcome assessment and $61(61 \%)$ were available for 6-month follow-up. Table 1 shows that baseline characteristics were similar in the 3 study groups.

Overall, 22 patients $(22 \%, 95 \%$ CI $13.9 \%-30.1 \%)$ had radiographic loss of reduction, including 5 (16\%, 95\% CI $3.1 \%-28.9 \%)$ in the VDS group, $8(20 \%, 95 \%$ CI $7.6 \%-32.4 \%)$ in the CC group and $9(30 \%, 95 \%$ CI $13.6 \%-46.4 \%$ ) in the MST group ( $p=0.17$ ). Only 2 patients underwent remanipulation by the orthopedic consultant, and 17 (17\%) went on to surgical fixation, including $2(6.5 \%)$ in the VDS group, $9(22.5 \%)$ in the cast group and $6(20 \%)$ in the MST group $\left(\chi^{2}[2 d f]=\right.$ $5.52, p=0.17)$. The remaining 3 patients who experienced loss of reduction at follow-up underwent no further operative intervention. Two-way comparisons between groups were not significant $(p>0.10)$ when analyzed using the Fisher exact test. Median pain scores based on a 5 -point categorical scale were similar among groups at all time points, with no significant differences, either at rest or with movement (Kruskal-Wallis ANOVA $H$ value $[2,77 d f=2.1] p=0.34)$. At 6 months, ROM was diminished in flexion $\left(14^{\circ}-16^{\circ}\right)$, extension $\left(12^{\circ}-14^{\circ}\right)$, supination $\left(10^{\circ}-18^{\circ}\right)$ and pronation $\left(6^{\circ}\right)$. Grip strength was also reduced by $7-10 \mathrm{~kg}$ compared with the

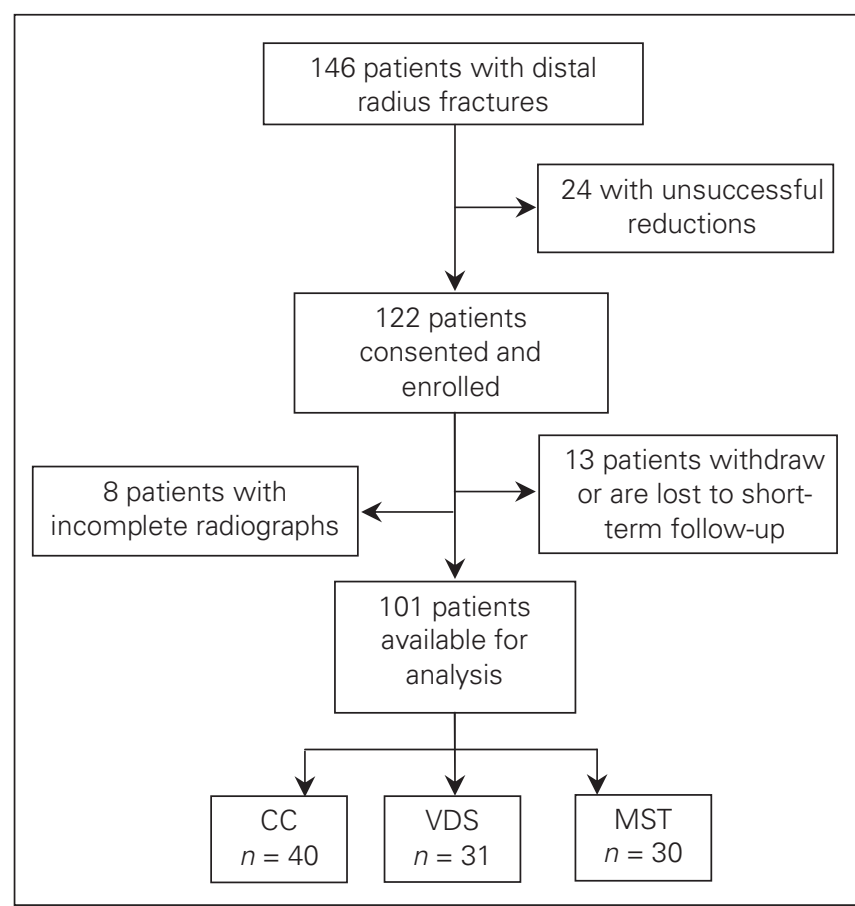

Fig. 5. Flow chart of study enrolment. $C C=$ circumferential cast; MST = modified sugar-tong; VDS = volar-dorsal splint. normal contralateral arm; however, based on MANOVA, no functional outcomes achieved statistical significance at 8 weeks $(12,138 d f ;$ Wilk lambda $=0.85 ; p=0.53)$ or 6 months $(10,116 d f$, Wilk lambda $=0.96 ; p=0.89)$.

Figure 6 shows the assessment of ADLs and RTW at 8 weeks and 6 months. There were no significant differences in ADLs or RTW at either time $\left(\chi^{2}[2 d f]<3.0\right.$, $p>0.20)$. DASH scores were determined for 58 patients (17 VDS, 23 CC and 18 MST) at 8 weeks (mean score 34.6) and for 51 patients (16 VDS splint, 20 CC and 15 MST) at 6 months (mean score 20.3). None of these differences were statistically significant for either period based on 1-way ANOVA ( $8 \mathrm{wk}: 2,57 d f ; F=0.81 ; p=0.45$ and $6 \mathrm{mo:} 2,50 \mathrm{df} ; F=0.01 ; p=0.99)$. Two patients developed carpal tunnel syndrome (1 VDS, 1 CC), 3 developed algoneurodystrophy (1 VDS, 1 MST) and 2 had persistent pain at 6 months (1 VDS, 1 MST). In addition, there were 2 cases of delayed union, both in the MST group.

\section{DISCUSSION}

To our knowledge, this is the first ED-based study to evaluate immobilization dressings for displaced Colles

\begin{tabular}{|c|c|c|c|}
\hline \multirow[b]{2}{*}{ Characteristic } & \multicolumn{3}{|c|}{ No. (\%) of patients* } \\
\hline & $\operatorname{VDS}(n=31)$ & $\operatorname{CC}(n=40)$ & $\operatorname{MST}(n=30)$ \\
\hline Female sex & $24(77)$ & $28(70)$ & $26(87)$ \\
\hline $\begin{array}{l}\text { Mean (SD) } \\
\text { age, yr }\end{array}$ & $56.3(21.3)$ & $57.6(20.4)$ & $59.4(17.6)$ \\
\hline $\begin{array}{l}\text { Ulnar styloid } \\
\text { fracture }\end{array}$ & $23(74)$ & $29(72)$ & $20(66)$ \\
\hline $\begin{array}{l}\text { Mean (SD) } \\
\text { dorsal } \\
\text { angulation, }{ }^{\circ}+\end{array}$ & $21.1(12.4)$ & $19.5(11.8)$ & $21.4(11.0)$ \\
\hline $\begin{array}{l}\text { Mean (SD) } \\
\text { radial } \\
\text { inclination, }{ }^{\circ}+\end{array}$ & $18.1(4.7)$ & $19.6(5.8)$ & $16.6(6.2)$ \\
\hline $\begin{array}{l}\text { Mean }(S D) \\
\text { ulnar variance, } \\
\text { mmt }\end{array}$ & $3.1(3.2)$ & $2.5(2.7)$ & $2.9(2.2)$ \\
\hline $\begin{array}{l}\text { DRUJ } \\
\text { involvement }\end{array}$ & $17(55)$ & $22(55)$ & $15(50)$ \\
\hline $\begin{array}{l}\text { Radiocarpal } \\
\text { joint } \\
\text { involvement }\end{array}$ & $15(48)$ & $17(42.5)$ & $13(43)$ \\
\hline $\begin{array}{l}\text { Dorsal } \\
\text { comminution } \neq\end{array}$ & $22(71)$ & $28(70)$ & 25 (83) \\
\hline \multicolumn{4}{|c|}{$\begin{array}{l}\mathrm{CC}=\text { circumferential cast; } \mathrm{DRUJ}=\text { distal radioulnar joint; } \mathrm{MST}=\text { modified sugar-tong; } \\
\mathrm{SD}=\text { standard deviation; } \mathrm{VDS}=\text { volar-dorsal splint. } \\
\text { *Unless otherwise stated. } \\
\text { †Before fracture reduction. } \\
\text { ‡Greater than } 1 / 3 \text { dorsal-volar diameter of radius on lateral view. }\end{array}$} \\
\hline
\end{tabular}


fractures requiring closed reduction. This study failed to demonstrate a statistically significant difference in loss of reduction among the 3 immobilization dressings.

Because the sample size calculation was predicated on an absolute difference of $20 \%$ in slippage rates among the groups as the minimum detectable difference, the observed disparities of $10 \%$ and $14 \%$ were not statistically significant. One could argue that the slippage rate for the VDS group (16\%) or CC group (20\%) compared with the MST group (30\%) is clinically, if not statistically, significant. The trend toward a higher slippage rate in the MST group may be explainable by the technically challenging nature of this procedure combined with the relative inexperience of the physicians with this technique. Regardless of statistical or procedural considerations, this trend toward increased slippage rates in the MST group and lack of functional benefits at any of the time points provides no justification to employ this complex technique.

Of particular relevance to clinicians is that this study failed to demonstrate that CC maintains a fracture position any better than a splint immobilization dressing. The overall slippage rate of $22 \%$ in our study is consistent with results obtained by Schmalholz, ${ }^{6}$ although another study noted a $30.8 \%$ rate of reduction loss, which was more pronounced $(37.5 \%)$ when junior house staff performed these. ${ }^{7}$ Use of strict radiographic criteria before study entry may have contributed to the lower rates of slippage observed in our study, compared with others. ' One randomized study compared a plaster cast with a light-weight removable wrist splint in patients with minimally displaced distal radius fractures not requiring reduction. ${ }^{8}$ Functional assessment at 6 weeks and patient satisfaction scores favoured the removable splint group ${ }^{8}$ but these fractures did not require manipulation.

In this study there were no differences in pain scores, ROM, ADLs or RTW among any of the immobilization groups. The DASH Outcome Measure is a 30 item, self-report questionnaire designed to measure physical function and symptoms in people with musculoskeletal disorders of the upper limb. The DASH Outcome Measure has exhibited both reliability and validity in different regions of the upper limb. ${ }^{9}$ Despite using this more complex functional measure, we could not identify important differences among the immobilization techniques.

Handoll and Madhok ${ }^{10}$ appraised the closed treatment of Colles fractures in a systematic review and concluded that practitioners should use "an accepted technique with which they are familiar." Van der Linden and Ericson $^{11}$ compared immobilization with casting versus dorsal splinting in various hand positions using 5 groups. Three groups had CC and 2 had dorsal splinting with various wrist positions. No difference was observed in final dorsal angulation and radial shift in the splint versus cast groups. Likewise, ROM compared with the contralateral limb was similar in the cast and splint groups. Some studies compare plaster cast to functional bracing for the treatment of either displaced or nondisplaced Colles fractures. Stewart and colleagues ${ }^{12}$ compared $^{2}$

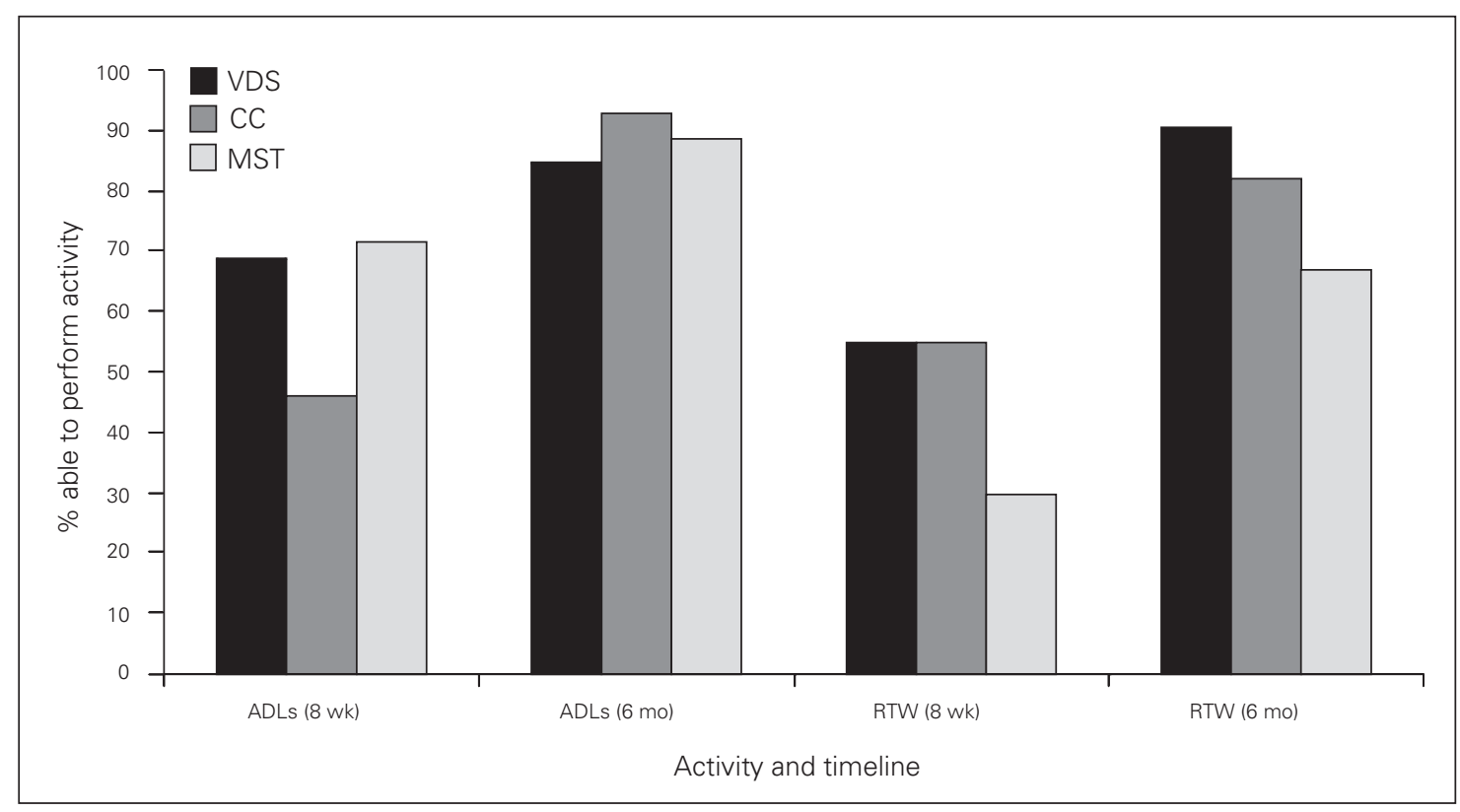

Fig. 6. Activities of daily living (ADLs) and return to work (RTW) at 8 weeks and 6 months. 
243 patients randomly assigned to 3 groups: CC, aboveelbow cast brace with the forearm in supination, and a below-elbow cast brace. Initially all were put in a radiodorsal slab and switched to one of the above groups at an average of 9 days after reduction. No difference was noted in anatomic position and functional outcome at 6 months. Moir and coauthors ${ }^{13}$ compared a prefabricated functional brace with a plaster of Paris cast in 85 patients with displaced Colles fractures. They found that both groups had similar loss of reduction. The brace group had a better functional result at 6 months. The baseline characteristics were slightly different in the 2 groups. Ledingham and colleagues ${ }^{14}$ also found in their study of 60 patients with displaced Colles fractures that the functional brace group had better anatomic and functional outcomes compared with the cast group. Other studies ${ }^{15-18}$ have found no difference between splint or bandage in the treatment of nondisplaced Colles fractures and one study even questions the need to reduce moderately displaced Colles fractures in elderly patients. ${ }^{19}$

\section{Limitations}

This study is limited by the fact that we did not reach our target sample size because of several reasons, including a shortage of funding and study fatigue in emergency physicians who were enrolling patients. The sample size of 101 patients provided $80 \%$ power to detect a relatively large effect size of $30 \%$ difference in slippage rates. Had we been able to reach our target sample size of 66 per group, the observed differences in slippage rates (10\% and $14 \%$, respectively) would still not have attained statistical significance.

With regard to functional outcomes, this study is sufficiently powered (80\%) to detect a difference between groups of 12 points in DASH score. This is close to the difference in mean score that would be considered a minimally important change in assessment of postoperative functional outcomes in some orthopedic surgeries. ${ }^{20}$ This is perhaps the most important outcome, because limb use would be of greatest concern to patients. Also, there exists a high degree of correlation between DASH score and radiologic outcomes. ${ }^{21}$

The lack of a difference in grip strength at 8 weeks and 6 months supports this conclusion that no one dressing is superior to another. This study had approximately $85 \%$ power to detect a moderate effect size $(0.6$ of the standard deviation of the difference in grip strength, or $3.5 \mathrm{~kg}$ ) between immobilization techniques.
No statistically significant difference between immobilization techniques was evident; however, the complexity of the MST technique and poorer performance argues against its continued use in this environment.

Although we attempted to report findings using the CONSORT (Consolidated Standards of Reporting Trials) guidelines, our inability to track consecutive patients represented another study limitation. Some patients declined to participate upon learning that they were randomly assigned to the MST group. Some patients were lost to follow-up. Both of these problems contributed to lower than expected enrolment numbers.

Although physicians at all sites were trained in the application of all dressings, different dressings were popular from the outset at different sites. This may have led to preferences and biases of the treating physicians.

The study coordinators who performed the functional assessments were not blinded to the immobilization group; however, these coordinators were not involved in the study design and had no vested interest in preferring one immobilization technique over another. We feel the influence of this bias was limited.

It is known that radiograph measurements tend to lack interrater reliability. ${ }^{20}$ Although we used measurements with the highest interrater reliability, it is possible that if several different physicians had interpreted the radiographs there may have been different outcomes for the anatomic assessment of slippage. However, given the similarity between groups, it is unlikely that this would have changed the overall conclusion of the study.

The lack of significant difference among the immobilization groups and the relative difficulty of moulding the splint material suggests that the final outcome is determined more by the fracture pattern and the quality of the initial reduction than by the immobilization dressing. Future studies should include multiple centres and a large sample size to verify these results.

\section{CONCLUSION}

Based on the results of this study we conclude that the type of immobilization dressing used for displaced distal radius fractures that are being treated nonoperatively does not alter the anatomic position of the fracture or the functional outcome. This represents one of the only randomized trials assessing CC versus splinting in the management of displaced Colles fractures. Without a detectable difference between the splinting and CC groups, treating physicians should choose the material and method they feel most comfortable with. 
Competing interests: None declared.

Funding: This study was funded through an unrestricted grant in aid from Smith \& Nephew, manufacturers of both the splint and cast material used in this study.

\section{REFERENCES}

1. Thompson PW, Taylor J, Dawson A. The annual incidence and seasonal variation of fractures of the distal radius in men and women over 25 years in Dorset, UK. Injury 2004;35:462-6.

2. Bucholz RW, Heckman JD, editors. Rockwood and Green's fractures in adults. 5th ed. Philadelphia (PA): Lippincott Williams and Wilkins; 2001. p. 118-28, p. 815-27.

3. Younger ASE, Curran P, McQueen MM. Backslabs and plaster casts: Which will best accommodate increasing compartmental pressures? Injury 1990;21:179-81.

4. Wytch R, Ashcroft GP, Ledingham WM, et al. Modern splinting bandages. J Bone Joint Surg Br 1991;73:88-91.

5. Aladin A, Earnshaw SA, Moran GC. Control of forearm rotation during nonoperative management of Colles' Fracture: a prospective randomized controlled trial. Monroe (NY): HWB Foundation; 2001. Available: www.hwbf.org/ota/am/ota01 /otapa/OTA01952.htm (accessed 2009 Mar. 18).

6. Schmalholz A. Closed reduction of axial compression in Colle's fractures is hardly possible. Acta Orthop Scand 1989;60: $57-9$.

7. Kakarlapudi TK, Santini A, Shahane SA, et al. The cost of treatment of distal radius fractures. Injury 2000;31:229-32.

8. O'Connor D, Mullett H, Doyle M, et al. Minimally displaced Colles' fractures: a prospective randomized trial of treatment with a wrist splint or a plaster cast. 7 Hand Surg [Br] 2003;28:50-3.

9. Hudak PL, Amadio PC, Bombardier C; Upper Extremity Collaborative Group. Development of an upper extremity outcome measure: the DASH (Disabilities of the Arm, Shoulder, and Hand). Am J Ind Med 1996;29:602-8.

10. Handoll HH, Madhok R. Conservative interventions for treating distal radius fractures in adults. Cochrane Database of Syst Rev. 2002;CD000314.

11. Van der Linden W, Ericson R. Colle's fracture. How should its displacement be measured and how should it be immobilized? J Bone Joint Surg Am 1981;63:1285-8.

12. Stewart HD, Innes AR, Burke FD. Functional cast-bracing for Colle's fractures. A comparison between cast-bracing and conventional plaster casts. 7 Bone Joint Surg Br 1984;66:749-53.

13. Moir JS, Murali SR, Wardlaw D, et al. A new functional brace for the treatment of Colle's fractures. Injury 1995;26:587-93.

14. Ledingham WM, Wytch R, Goring CC, et al. On immediate functional bracing of Colle's fracture. Injury 1991;22:197-201.

15. Dias JJ, Wray CC, Jones JM, et al. The value of early mobilization in the treatment of Colle's fractures. J Bone Joint Surg $\operatorname{Br} 1987 ; 69: 463$.

16. Stoffelen D, Broos P. Minimally displaced distal radius fractures: Do they need plaster treatment? J Trauma 1998;44:503-5.

17. Ferris BD, Thomas NP, Dewar ME, et al. Brace treatment of Colle's fracture. Acta Orthop Scand 1989;60:63-5.

18. de Bruijn HP. Functional treatment of Colle's fractures. Acta Orthop Scand 1987;58(Suppl 223):27-51.

19. Kelly AJ, Warwick D, Crichlow TPK, et al. Is manipulation of moderately displaced Colle's fractures worthwhile? A prospective randomized trail. Injury 1997;28:283-7.

20. Gummesson C, Atroshi I, Ekdahl C. The disabilities of the arm, shoulder and hand (DASH) outcome questionnaire: longitudinal construct validity and measuring self-rated health change after surgery. BMC Musculoskelet Disord 2003;4:11.

21. Wilcke MK, Abbaszadegan H, Adolphson PY. Patientperceived outcome after displaced distal radius fractures. A comparison between radiological parameters, objective physical variables, and the DASH score. 7 Hand Ther 2007;20:290-8.

Correspondence to: Dr. Rob Stenstrom, Emergency Department, St. Paul's Hospital, 1081 Burrard St., Vancouver BC V6Z 1Y6; robstenstrom@shaw.ca 